UDK 52Lemaître, G. $524.85: 11$ https://doi.org/ 10.31337/oz.73.4.4 Pregledni rad Primljeno 7.9.2018. Prihvaćeno 3.12.2018.

\title{
Lemaîtreov praatom
}

Roko Pešić*

In principio creavit Deus caelum et terram.

(Post 1,1)

\begin{abstract}
Sažetak
U radu je predstavljena kozmološka hipoteza o praatomu — prethodnica teorije velikog praska (Big Bang) o početku svemira — belgijskog svećenika i profesora fizike Georgesa Lemaîtrea, inače Einsteinova suvremenika, kojega nazivaju $i$ "ocem teorije velikog praska". Važnost te hipoteze u tome je što je ona, proizišavši iz djelomično korigiranih Einsteinovih jednadžbi svemira, prvi znanstveno i matematički obrazložen, a kasnije i eksperimentalno potvrđen kozmološki model početka i razvoja svemira koji se širi. Time je do tada općeprihvaćeni tzv. statički model svemira postao neodrživ. Rad se temelji na engleskom prijevodu izvornog Lemaîtreovog teksta, te je popraćen bilješkama i pojašnjenjima stručnih pojmova. U uvodu te u većem dijelu rada ukratko se opisuje Lemaîtreova glavna ideja koja se zasniva na pojmu prostora promjenjivog polumjera, pretpostavci radioaktivnog podrijetla jednog dijela kozmičkih zraka i zakona razgradnje energije (drugog zakona termodinamike). Opisana je uloga Einsteinove kozmološke konstante, interakcija gravitacijske sile i kozmičkog odbijanja, kao i kasnija evolucija svemira, formiranje oblaka plina, zvijezda i galaksija. U zadnjem odlomku pod naslovom Stvaranje ili početak te u zaključku iznesen je komentar autora ovog rada o filozofskim i metafizičkim implikacijama Lemaîtreove hipoteze te o njezinu znanstvenom utjecaju $i$ važnosti.
\end{abstract}

Ključne riječi: praatom, radioaktivni raspad, veliki prasak, kozmološki model, Georges Lemaître, širenje svemira

* Mr. sc. Roko Pešić, Nacionalna i sveučilišna knjižnica u Zagrebu. Adresa: Ulica Hrvatske bratske zajednice 4, p.p. 550, 10000 Zagreb, Hrvatska. E-adresa: roko.pesic@gmail.com 


\section{Uvod}

Georges Edouard Lemaître ${ }^{1}$ preinakom Einsteinovih jednadžbi svemira (Lemaître, 1927, 49-59), iznio je kozmogonijsku² hipotezu koja opisuje sadašnji svemir kao rezultat radioaktivnog raspada atoma, ili — kako ga je on nazvao - praatoma (Lemaître, 1950, 339). Iste je jednadžbe neovisno, nekoliko godina prije Lemaîtrea, na isti način riješio i ruski fizičar Alexander Friedmann, ali rješenje nije interpretirao u smislu širenja stvarnog, astronomskog svemira, nego kao jedan od nekoliko teoretski mogućih kozmoloških modela (Tauber, 1984, 374). Do tada je, naime, vladalo stoljetno opće uvjerenje novovjekovnih znanstvenika da je svemir statičan, nepromjenljiv i vremenski neograničen, tj. da nema početka ni kraja. U statički svemir bio je uvjeren čak i Einstein — njegov prvi kozmološki model razvijen u okviru opće teorije relativnosti opisivao je sferni i savršeno statički svemir. Međutim, nakon Hubbleova astronomskog otkrića (Hubble, 1929, 168) svesrdno je podržao Lemaîtreovu teoriju (Lambert). Osim uz pomoć opće teorije relativnosti, Lemaître je do te hipoteze došao, kako sam kaže, razmatranjem zakona degradacije energije ${ }^{3} \mathrm{u}$ okviru tada već poznate kvantne teorije. Otkrića prirodne i laboratorijski generirane radioaktivnosti, kao i korpuskularne prirode kozmičkih zraka, naveli su ga na pretpostavku radioaktivnog podrijetla tih zraka i cjelokupne postojeće materije. Tom pretpostavkom mogu se, istina, samo dijelom, objasniti ne samo kozmičke zrake, nego i sadašnja struktura svemira, koji se sastoji od zvijezda i oblaka plina, organiziranih u spiralne i eliptične maglice, ${ }^{4}$ koje se udaljavaju jedna od druge prema mehanizmu poznatom pod imenom ekspandirajućeg svemira (svemira koji se širi).

\section{Geometrija Svemira}

Lemaître uvodi neke osnovne geometrijske pojmove, kao što je primjerice Riemannov $^{5}$ zatvoreni prostor, pomoću kojega je uveo koncept svemira promjen-

1 Georges Edouard Lemaître (1894.-1966.), belgijski svećenik i astronom, profesor fizike na Katoličkom sveučilištu u Leuvenu i član suradnik Kraljevskog astronomskog društva u Londonu, član Papinske akademije znanosti u Rimu. Poznat je po ideji praatoma ili "svemirskog jajeta", prema kojoj je svemir nastao iz nezamislivo gustog i toplog stanja cjelokupne materije svemira zbijene u jednu jedinu praiskonsku česticu. Postupnim širenjem svemira materija se hladila i diferencirala, stvarajući kompleksnu strukturu svemirskih objekata — planeta, zvijezda, zvjezdanih skupova, galaksija i dr., koju danas opažamo. Ta se ideja s vremenom razvila u danas popularnu i još uvijek važeću teoriju velikog praska (engl. Big Bang), koja je višestruko potvrđena (radio)astronomskim mjerenjima i opažanjima, iako postoje neka neriješena teoretska pitanja, na koje ona za sada ne može dati konačan odgovor (Encyclopaedia Britannica).

2 Kozmogonijski - koji se odnosi na podrijetlo i razvoj svemira.

3 Zakon degradacije energije - drugi zakon termodinamike koji u jednoj od formulacija glasi: Toplina spontano može prelaziti samo s toplijeg na hladnije tijelo. Prelaskom topline iz toplijega spremnika u hladniji samo se dio topline pretvara u rad, a ostatak topline prelazi u spremnik niže temperature. Ta energija je degradirana u smislu da se više ne može vratiti u prvobitno stanje, odnosno iskoristiti za vršenje rada.

4 Maglice - autor misli na galaktike.

5 Georg Fridrich Bernhard Riemann (1826.-1866.) njemački matematičar, između ostalih važnih doprinosa matematici, poznat i po formuliranju tzv. neeuklidske geometrije (različitu od obične, 
ljivog polumjera (Lemaître, 1931, 483), a također koristi neke postavke tada već poznate Einsteinove opće teorije relativnosti, primjerice kozmološku konstantu, ${ }^{6}$ koja označava kozmičku repulziju. ${ }^{7}$

Zatvoreni šireći svemir možemo pojednostavljeno predočiti kao dvodimenzionalni prostor sfere. Lako ga je predočiti kao balon koji se napuhuje. Ako krenemo iz neke proizvoljne točke A koja se nalazi na sferi, gibajući se stalno u istom smjeru, vratit ćemo se u tu istu točku A iz protivnog smjera. Autor dalje uvodi pojam prostora koji ima promjenljivi polumjer. Sve točke u prostoru su potpuno ekvivalentne, što znači da će za svakog motritelja prostor izgledati jednako, bez obzira gdje se on nalazio, pa će svaki od tih motritelja moći načiniti istu kartu svemira. Ako se polumjer prostora povećava u vremenu, svaki motritelj vidi da se sve točke koje ga okružuju, udaljavaju od njega to većim brzinama što su udaljenije. To je upravo ono što su astronomi zapazili za vangalaktičke maglice (tj. maglice izvan naše galaktike Mliječnog puta) koje nas okružuju. Konstantni omjer između njihove brzine udaljavanja i udaljenosti od Zemlje odredili su astronomi Hubble i Humason. ${ }^{8}$ Recipročna vrijednost tog omjera ima dimenziju vremena i daje procjenu starosti svemira 20 milijardi godina (pod pretpostavkom da se svemir širi stalnom brzinom) (Lemaître, 1950, 342).

Lemaître, inspiriran tada već dobro poznatom pojavom radioaktivnosti, zamišlja da je u pradavno doba čitav svemir postojao u obliku atomske jezgre koja je jednoliko ispunjavala prostor.

Kozmogonijske teorije temelje se na istraživanju sasvim jednostavnih početnih uvjeta iz kojih je mogao nastati svemir u čitavoj svojoj kompleksnosti, kroz međudjelovanje poznatih prirodnih sila. Takve jednostavne početne uvjete dobivamo kada je sva materija bila zgusnuta u atomskoj jezgri. Ta je atomska jezgra, ipak, morala biti sustav u kojem vezane čestice još uvijek zadržavaju određenu vlastitu individualnost. Činjenica da čestice mogu izletjeti iz jezgre tijekom radioaktivnih transformacija ne dokazuje da su one kao takve postojale i prije (tih transformacija). Primjerice iz atoma izlijeću fotoni ${ }^{9}$ koji nisu bili njegovi sastavni dijelovi, a iz atomske jezgre izlijeću elektroni koji u njoj ne egzistiraju. Radioaktivni raspad je tipičan primjer degradacije energije, praćen povećanjem neovisnih kvanata energije, ${ }^{10}$ odnosno povećanjem entropije. Entropija je fizikalna veličina koja mjeri neuređenost s kojom je energija uskladištena u nekom

euklidske geometrije) po njemu nazvane Riemannovom geometrijom, koja je našla primjenu u Einsteinovoj općoj teoriji relativnosti.

6 To je konstanta koju je uveo Einstein da bi opravdao model statičkog svemira koji se ne urušava, homogen je i izotropan. Njezina pozitivna vrijednost označava zamišljenu odbojnu silu koja se suprotstavlja privlačnoj gravitacijskoj sili.

7 Repulzija je odbijanje.

8 Taj omjer poznat je pod nazivom Hubbleova konstanta, čija se vrijednost nalazi u intervalu 60-70 km/s/Mpc (Vujnović, 2004, 71). Mpc je kratica za megaparsek, mjerna jedinica za goleme svemirske udaljenosti, iznosi oko $3 \times 10^{19} \mathrm{~km}$.

9 Fotoni, kvanti elektromagnetskog zračenja u koje spada i vidljiva svjetlost.

10 Kvant energije je najmanja količina (obrok) energije koju atom, molekula ili atomska jezgra može apsorbirati ili emitirati. 
sustavu. Što je veća neuređenost, veća je entropija (Lopac, 2009, 70). Entropija i ukupni broj fotona su proporcionalni trećoj potenciji temperature. ${ }^{11}$ Degradacija energije očituje se, dakle, kao "usitnjavanje" energije, što znači da je ukupna energija očuvana, ali je raspodijeljena na sve veći broj kvanata. Taj proces možemo donekle usporediti sa staklenom čašom koja padne sa stola na pod i pri tome se "razbije" u mnoštvo komadića (=kvanata), te pri tome dolazi do povećanja entropije. Ako, dakle, u mislima pokušamo "odvrtjeti” film razvoja svemira unatrag u vremenu, doći ćemo u prošlosti do trenutka kada je cjelokupna energija svemira bila koncentrirana u najmanjem broju kvanata, tj. u jednom jedinom kvantu. To početno, primordijalno stanje moralo je biti stanje najveće koncentracije energije i minimalne entropije. Upravo u pokušaju formuliranja tog uvjeta rođena je ideja praatoma.

\section{Formacija oblaka plina}

U početku je praatom ispunjavao sićušni prostor i bio je nalik na nešto poput atomske jezgre, odnosno električki neutralan poput neutrona. Zamišljamo da je postojao samo trenutak, u stvari da je bio nestabilan i odmah se raspao u djeliće koji su se dalje raspali u još sitnije djeliće: iz praatoma su tako izletjeli elektroni, protoni, alfa čestice itd. (Lemaître, 1950, 343). Nekakvu (vrlo pojednostavnjenu) analogiju toga raspada imamo kod tzv. beta-raspada slobodnog neutrona koji se s poluživotom od približno 15 minuta raspadne u proton, elektron i elektronski neutrino. Taj raspad je uzrokovao naglo povećanje polumjera prostora koji su jednoliko ispunjavali djelići (raspadnutog) praatoma. Kada su ti djelići postali stabilni, prestali su se dalje cijepati. Samo neki među njima, poput urana, još se uvijek sporo raspadaju, sa srednjim poluživotom ${ }^{12}$ od četiri milijarde godina, ostavljajući nam oskudni "pepeo" opće dezintegracije koja se dogodila u početku vremena. U toj početnoj fazi širenja prostora, čestice se gibaju golemim brzinama bliskim brzini svjetlosti, koje su rezultat odboja ${ }^{13}$ u trenutku emisije zračenja. Te su čestice uronjene u zračenje velike energije koje ispunjava sav prostor. Naime, golema energija sadržana u praatomu tada je velikim dijelom još bila sadržana u zračenju (zbog kubne ovisnosti broja fotona o temperaturi). Uslijed naglog širenja prostora, energija i brzine čestica izbačenih iz praatoma postupno su se smanjile (kao što zrna sačme sa sve većim udaljavanjem od mjesta njihova ispaljenja uslijed otpora zraka postupno usporavajući, gube kinetičku energiju)

11 Iz termodinamičkih proračuna energije zračenja crnog tijela odnosno iz Stefan-Boltzmannova zakona dobiva se da su broj fotona i entropija crnog tijela proporcionalni trećoj potenciji termodinamičke temperature izražene u stupnjevima Kelvina.

12 Poluživot ili vrijeme poluraspada je vrijeme nakon kojega se broj jezgara radioaktivnoga elementa smanji na polovicu.

13 Odboj je pojava da prilikom emisije zračenja u određenom smjeru, mirna čestica odnosno atomska jezgra koja je emitirala zračenje odleti u suprotnom smjeru, što je posljedica očuvanja zaleta (količine gibanja). Pri tome je umanjena ukupna energija čestice u odnosu na njezinu početnu energiju, i to za iznos energije koju odnosi zračenje. 
pa tada i sudari među česticama postaju dovoljno ublaženi da ne izazovu atomske transformacije ili emisije zračenja, nego će ti sudari biti elastični (usp. bilj. 22). Tako će, barem lokalno, na pojedinim mjestima, nastati plin u statističkoj ravnoteži gdje će čestice plina početi sve više osjećati djelovanje gravitacijske sile da bi se postupno formirali oblaci plina. Ti plinoviti oblaci bit će pomiješani sa zračenjem čija je energija također smanjena ekspanzijom prostora. To je upravo ono zračenje koje će se održati sve do današnjeg vremena u obliku kozmičkih zraka $^{14}$ (Lemaître, 1950, 343-344), a od plinovitih oblaka će se (puno kasnije) formirati zvijezde i maglice.

\section{Kozmička repulzija}

Dvije godine nakon što je Lemaître iznio svoju teoriju širećeg svemira, tj. godine 1929., ona je dobila i uvjerljivi empirijski dokaz. Naime, te godine američki astronom Edwin Hubble eksperimentalno je potvrdio da se bliže galaktike udaljavaju od Zemlje brzinom koja je razmjerna njihovoj udaljenosti od Zemlje, što je poznato kao Hubbleov zakon. Time je oboreno tisućljetno opće uvjerenje znanstvenika i filozofa o tzv. statičnom, nepromjenljivom svemiru koji nema vremenski početak i kraj.

Prije spomenutu kozmološku konstantu (uobičajeno označenu velikim grčkim slovom lambda: $\Lambda$ ) u jednadžbama gravitacijskog polja uveo je Einstein da bi opravdao model statičkog svemira (Tauber, 1984, 433) koji se ne urušava, homogen ${ }^{15}$ je i izotropan, ${ }^{16}$ unatoč tomu što njegove jednadžbe u općoj teoriji relativnosti nisu dopuštale takav (tj. statički) model svemira, nego su kao rezultat davale dinamički svemir koji se širi. Konstanta $\Lambda$ može biti pozitivna, negativna i jednaka nuli. Njezina pozitivna vrijednost označava kozmičku repulziju — dodatnu odbojnu silu proporcionalnu udaljenosti među galaktikama, koja se suprotstavlja privlačnoj gravitacijskoj sili (Vujnović, 2004, 84). Prema općoj teoriji relativnosti pozitivna kozmološka konstanta opisuje ubrzano širenje praznog prostora. $^{17}$

Nakon prve faze brzog širenja slijedio je period usporavanja, tijekom kojega su se privlačna i odbojna sila postupno uravnotežile. Napokon je kozmička repulzija nadvladala gravitacijsku silu, i svemir je ušao u treću fazu u kojoj se nastavlja širiti uslijed prevladavajućeg djelovanja odbojne sile (Slika 1).

14 Lemaitre iznosi dalekosežnu pretpostavku o mogućem postojanju tada još neotkrivenog kozmičkog pozadinskog zračenja u mikrovalnom području koje dolazi iz svemira podjednako raspršeno iz svih smjerova i koje potječe iz ranog doba svemira. Spektar tog zračenja odgovara spektru crnog tijela temperature 2,73 stupnjeva Kelvina.

15 Posvuda je jednake gustoće.

16 Ima jednaka svojstva u svim smjerovima.

17 Einstein je poslije isključio kozmološku konstantu iz svojih jednadžbi i nazvao ju je svojom "najvećom pogreškom”. No, opažanja relacije između udaljenosti i crvenog pomaka galaktika, načinjena 90-ih godina 20. stoljeća ukazala su na ubrzano širenje svemira koje se može dobro objasniti ako se pretpostavi vrlo mala pozitivna kozmološka konstanta u Einsteinovim jednadžbama. 
Iz termodinamičkih razmatranja proizlazi da oblaci plina nisu mogli biti raspoređeni savršeno jednoliko, pa su tako postojala dovoljno mala područja prostora u kojima je privlačna sila nadvladala odbojnu, unatoč pretpostavci da se svemir kao cjelina širio. U takvoj situaciji imamo svemir koji se sastoji od zgusnutih područja koja su odvojena jedna od drugih. Ta zgusnuta područja su zametci budućih zvijezda, skupova zvijezda i galaksija.

Međutim, velika područja prostora — gdje gustoća ili brzina širenja neznatno odstupaju od prosječnih vrijednosti pa je zato moguće kolebanje između širenja i sažimanja — ostala su u ravnoteži, a svemir se nastavio širiti. Ta velika područja Lemaître je poistovjetio s nakupinama maglica (danas bismo rekli: jatima galaktika) koje su ostale u ravnotežnoj fazi i predstavljaju uzorak raspodjele tvari kakva je postojala posvuda u svemiru dok je njegov polumjer bio desetak puta manji nego u sadašnjem trenutku.

Do slične je brojčane vrijednosti za sadašnji polumjer svemira $\left(R=10^{10}\right.$ godina svjetlosti), osim Einsteina, neovisno došao i De $\operatorname{Sitter}^{18}$ (Lemaître, 1950, 349), iako je on postavio sasvim drukčiju hipotezu od Einsteinova modela.

\section{Formiranje zvijezda i galaksija}

Gustoća prije spomenutih plinovitih oblaka u stanju termodinamičke ravnoteže iznosila je, u prosjeku, $10^{-27} \mathrm{~g} / \mathrm{cm}^{3}$ (Lemaître, 1950, 349). Radi zornosti recimo da bi, uz tu gustoću, kugla plina mase našeg Sunca imala polumjer sto godina svjetlosti. Oblaci tako male gustoće nemaju tendenciju sažimanja, jer je njegova gravitacijska sila preslaba da bi prouzročila zgušnjavanje plina. Da bi sažimanje uslijed gravitacije moglo započeti, njihova se gustoća mora znatno povećati, što se može dogoditi ako se dva takva oblaka sudare pri velikim brzinama.

Tijekom kontakta oni će se spljoštiti i gustoća će im se povećati, a tada je dovoljna i najmanja početna rotacija koja se sažimanjem može jako povećati uzimajući u obzir da ukupni zamah ${ }^{19}$ (=kutna količina gibanja) (Lopac, 2009, 126) oblaka tijekom sažimanja mora biti očuvan. ${ }^{20}$ Može se pokazati da takva rotacija nije spojiva sa formiranjem samo jednog tijela, nego višestrukih zvijezda koje se okreću jedne oko drugih, ili jedne zvijezde s jednim ili više velikih planeta koji se okreću u istom smjeru. Međusobnim neelastičnim sudarima ${ }^{21}$ oblaci plina gube energiju i zgušnjavaju se, što može dovesti do formiranja zvijezde, eliptične magli-

18 Willem de Sitter (1872.-1934.), nizozemski matematičar, fizičar i astronom koji je razvio kozmološki model ravnog svemira s homogenim prostorom bez materije koji se eksponencijalno širi, po njemu nazvan De Sitterov model.

19 Zamah je fizička veličina koja opisuje rotaciju čestice ili krutog tijela.

20 Analognu pojavu vidimo kod klizačice na ledu koja, da bi ubrzala rotaciju tijela mora ruke, $u$ početku raširene, mora priljubiti uz tijelo.

21 Neelastični sudar je sudar dvaju tijela u kojem ukupna količina gibanja ostaje očuvana, dok se dio kinetičke energije gubi u okolinu ili se troši na zagrijavanje, odnosno na promjenu oblika ili sastava tijela, za razliku od elastičnog sudara u kojem su očuvane i količina gibanja i ukupna kinetička energija. 
$\mathrm{ce}^{22}$ ili plosnatog sustava nalik Saturnovu prstenu ili planetnom sustavu, nečemu što podsjeća na spiralnu maglicu ${ }^{23}$ nalik našoj galaktici Kumovoj slami (Mliječnomu putu) (Vujnović, 2004, 86). Spiralni ili eliptični oblik maglice ovisi o iznosu zamaha u području zgušnjavanja oblaka. Tip pojedine zvijezde određen je iznosom njezine mase, koja je jednaka zbroju masa oblaka čiji sudar je proizveo zvijezdu.

\section{Stvaranje ili početak}

Lemaîtreova hipoteza praatoma ili "kozmičkog jajeta” otvara neizbježne metafizičke implikacije, jer postulira da je svemir započeo postojati u vremenu pa se nameće pitanje, otkuda se to jaje "dokotrljalo"? Naime, Aristotelov pojam prvog

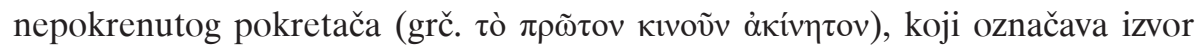
svakog kretanja, savršeno biće, prauzrok svih stvari (Rječnik filozofskih pojmova, s. v. nepokrenuti pokretač), tu dopušta i Božji stvarateljski čin.

Međutim, pitanje je li to uistinu bio stvarni početak ili pak stvaranje ex nihilo, nešto što je počelo ni iz čega, filozofsko je pitanje koje nije moguće postaviti u okvirima fizičkih ili astronomskih razmišljanja, a to i nadilazi temu ovog rada.

Mnogo kasnije od hipoteze o. Lemaîtrea, u novije doba, postavljene su drugačije kozmološke teorije, primjerice teorija struna, zatim teorije o multiverzumima, oscilirajućem svemiru i dr., ${ }^{24}$ koje matematičkim formalizmom teorijske fizike pokušavaju izvesti da svemir nema vremenskog početka. Međutim, one (još) nisu eksperimentalno potvrđene, pa za sada ostaju na području znanstvene spekulacije. Naime, prema danas dostupnim saznanjima i podatcima o vrijednostima fizikalnih parametara neposredno nakon trenutka velikog praska i danas, moguće je procijeniti koliki je porast ukupne entropije svemira. Iz te činjenice, kao i iz drugog zakona termodinamike, slijedi da je evolucija svemira nepovratan (ireverzibilan) proces čija entropija stalno raste (Pešić, 2011, 178). Upravo je ta, već spomenuta, degradacija ukupne energije svemira i nadahnula Lemaîtrea za njegovu hipotezu, ekstrapolacijom sadašnjeg stanja svemira u prošlost.

Zanimljivo je spomenuti da i poznati znanstvenici kao primjerice Einstein, Hawking (Hawking, 1988, 130), Hoyle (Tauber, 1984, 362), ali i neki današnji fizičari (Veneziano, 2012, 78) nisu prihvaćali, odnosno ne prihvaćaju (prvenstveno filozofske i metafizičke) implikacije velikoga praska kao stvarnog početka svemira, iako je danas ta činjenica uglavnom prihvaćena u znanstvenoj javnosti. Einstein je kasnije, doduše, prihvatio Lemaîtreovu hipotezu, pa se čak i pohvalno izrazio o njoj. Ali njegov zaključak bio je da se objašnjenje vremenskog početka svemira odnosno suštine samog vremena ne može naći unutar fizike (Ridgen, 2003, 195).

22 Eliptične maglice su galaktike koje imaju oblik elipsoida ili kugle.

23 Spiralne maglice su galaktike oblika diska sa središnjim ispupčenjem oko kojega se ovijaju spiralni krakovi.

24 Suprotno teoriji struna, koja uvodi nove, skrivene prostorne dimenzije, proračuni teoretske nebeske mehanike pokazuju da jedino u tri dimenzije gravitacijska sila ima takav oblik da osigurava stabilne putanje planeta Sunčevog sustava, a time i opstanak života na Zemlji (Morandini, 2012, 97-98). 
Smatram da u tome (tj. spomenutim filozofskim, odnosno metafizičkim pitanjima koja potencijalno proizlaze iz njegove hipoteze) donekle leži i uzrok nedovoljne Lemaîtreove znanstvene valorizacije i popularnosti, iako je on po prirodi bio skromna osoba i nije težio svjetskoj slavi, nego je u svojoj osobi na jedinstveni način savršeno uskladio znanost i vjeru, te je pokazao da one nikako nisu suprotstavljene jedna drugoj, nego mogu biti dobre suradnice u osvajanju novih obzora ljudske spoznaje.

\section{Zaključak}

Rješavanjem Einsteinovih jednadžbi s tlakom koji uzrokuje zračenje, uz uvjet da prije spomenuta kozmološka konstanta ima pozitivnu vrijednost, Lemaître je dobio svoj čuveni model svemira koji se širi i u čijem je početku praatom.

Hipoteza praatoma, osim što tumači okupljanje zvijezda u galaktike unutar svemira koji se širi, objašnjava i kvantitativni sastav tvari, odnosno relativnu zastupljenost različitih kemijskih elemenata na Suncu, zvijezdama, na Zemlji i u meteorima. Naime, prema Lemaîtreovoj hipotezi, produkti raspada praatoma u prirodi se nalaze $u$ točno određenim omjerima, koji su određeni zakonima radioaktivnih transformacija, što je poslije zaista i dokazano analizom spektara zvjezdane svjetlosti. Nadalje, analogijom sa zračenjem koje proizvode današnji radioaktivni raspadi, ta je teorija predvidjela postojanje sveprožimajućih ultraprodornih kozmičkih zraka radioaktivnog podrijetla koje su proizvedene tijekom raspada praatoma, u prvom razdoblju ekspanzije svemira. Te zrake s pravom se mogu nazvati fosilnim kozmičkim zrakama, jer su dokaz praiskonske aktivnosti svemira. Na svojem putu kroz svemir tijekom milijardi godina te zrake su nam donijele svjedočanstvo o superradioaktivnoj eri na samom početku svemira (Lemaître, 1950, 352-353). Koliko je o. Lemaître bio ispred svojeg vremena svjedoči i činjenica da je samo godinu dana prije njegove smrti, četrdesetak godina nakon što je objavio svoj rad (Lemaître, 1927), gotovo slučajno (!) otkriveno kozmičko pozadinsko mikrovalno zračenje, ${ }^{25}$ što je, osim Hubbleovog otkrića, bila jedna od ključnih eksperimentalnih potvrda teorije velikog praska (Lopac, 2009, 228), koja je direktna sljednica hipoteze praatoma. Inače, to zračenje čini samo mali dio ukupnog kozmičkog zračenja koje zapljuskuje Zemlju iz svemira, a potječe iz različitih svemirskih izvora: djelomično sa Sunca, iz naše galaktike i drugih galaktika, kvazara, ${ }^{26}$ eksplozija supernova ${ }^{27}$ itd. Zbog svojeg malenog udjela u ukupnom kozmičkom zračenju bilo ga je vrlo teško registrirati, pa je važnost toga otkrića tim veći.

25 Američki radioastronomi Arno Allan Penzias i Robert Woodrow Wilson izgradili su prijamni sustav (posebne antene) za detekciju radiovalova, kojim su 1965. godine otkrili kozmičko pozadinsko mikrovalno zračenje (Penzias i Wilson, 1965) te time potvrdili Lemaitreovu teoriju praatoma odnosno teoriju velikog praska (Big Bang) kao ispravnu i još uvijek važeću teoriju o početku svemira. Za to otkriće dobili su 1978. godine Nobelovu nagradu.

26 Kvazar je kvazizvjezdani objekt, galaktika s izrazito sjajnom zvjezdolikom jezgrom čija je snaga zračenja mnogo puta (do 1000) veća od obične galaktike.

27 Eksplozija supernove je eksplozija zvijezde praćena snažnim bljeskom i zračenjem velikih količina energije. 
Time je o. Lemaître dobio stručnu i moralnu satisfakciju za svoj epohalni doprinos suvremenoj astrofizici i kozmologiji. Smatram da se njega, koji je uz Einsteina, Hubblea, Hawkinga i druge velike astronome, fizičare i kozmologe, tvorac nove znanstvene paradigme o evoluciji svemira, po svojem doprinosu suvremenoj kozmologiji može s pravom usporediti sa našim Ruđerom Boškovićem. Zahvaljujući spomenutim znanstvenim otkrićima na području kozmologije i suvremenim astronomskim eksperimentalnim metodama, danas možemo svjetlom našega razuma "motriti" početak svemira kao što u zoru u smjeru istočnog obzora s udivljenjem motrimo purpurno-crvenkasti odsjaj koji najavljuje izlazak sunca. No, sam početak, odnosno trenutak Božjeg stvaranja svemira, unatoč velikim dosezima suvremene znanosti, ljudskoj spoznaji ostaje i dalje nedokučiv, s obzirom na to da znanost nikada neće moći objasniti što se točno dogodilo u samom trenutku velikog praska, jer prije tzv. Planckova vremena, koje iznosi $10^{-44}$ sekundi, ne vrijedi ni jedan poznati zakon fizike.

Zaključno, navedimo Lemaîtreovo mišljenje o odnosu njegove hipoteze prema vjeri, koje je napisao kao predsjednik Papinske Akademije znanosti: »Koliko mogu vidjeti, takva teorija ostaje u potpunosti izvan bilo kakvog metafizičkog ili vjerskog pitanja. Ona ostavlja materijalistu slobodu da poriče bilo koje transcendentalno biće [...]. Za vjernika ona uklanja svaki pokušaj familijarnosti s Bogom [...]. Ona je suglasna s Izaijinim govorom o skrivenom Bogu, skrivenom u samom početku svemira«.

\section{Prilog:}

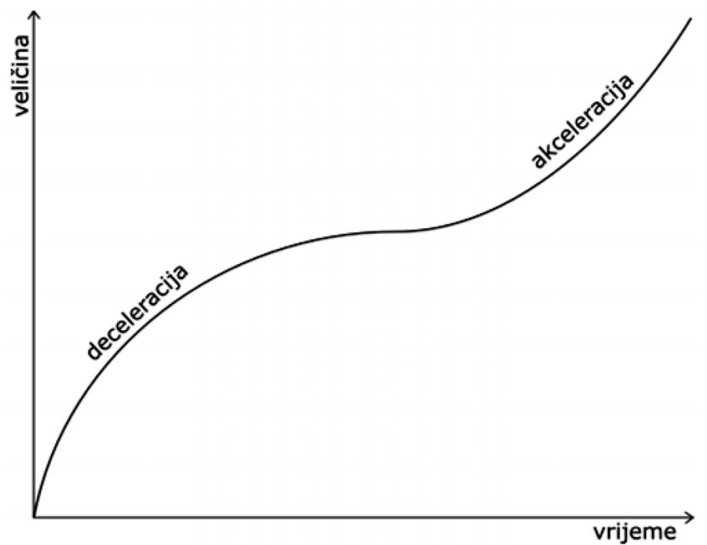

Slika 1. Širenje Lemaîtreovog svemira

Figure 1. Expansion of Lemaître's universe

Lemaîtreov svemir počinje naglim širenjem od početnog trenutka velikog praska kao jedan od Friedmannovih svemira, usporava do približno statičkog svemira, prije nego što se počne ubrzano širiti, i tako postaje sve više poput de Sitterova svemira 


\section{Literatura:}

Encyclopaedia Britannica. URL: https://www.britannica.com/biography/Georges-Lemaitre (13.09.2018.)

Hawking, Stephen W. (1996). Kratka povijest vremena: Od velikog praska do crnih jama. Zagreb: Izvori.

Hubble, Edwin (1929). A relation between distance and radial velocity among extra-galactic nebulae. Proceedings of the National Academy of Sciences of the United States of America, 15(3), 168-173.

Lambert, Dominique. Einstein and Lemaître: two friends, two cosmologies... U: Interdisciplinary Encyclopedia of Religion \& Science. URL: http://inters.org/einstein-lemaitre (16.10.2018.)

Lemaître, Georges (1927). Un Univers homogène de masse constante et de rayon croissant rendant compte de la vitesse radiale des nébuleuses extra-galactiques. Annales de la Société Scientifique de Bruxelles, A47, 49-59.

Lemaitre, Georges (1931). Expansion of the universe: A homogeneous universe of constant mass and increasing radius accounting for the radial velocity of extra-galactic nebulae. Monthly Notices of the Royal Astronomical Society, 91(3), 483-490.

Lemaître, Georges (1950). The Primeval Atom: An Essay on Cosmogony. New York: Van Nostrand.

Lopac, Vjera (2009). Leksikon fizike. Zagreb: Školska knjiga.

Morandini, Simone (2012). Teologija i fizika. Zagreb: Kršćanska sadašnjost.

Penzias, Arno Allan; Wilson, Robert Woodrow (1965). A Measurement of Excess Antenna Temperature at $4080 \mathrm{Mc} / \mathrm{s}$. Astrophysical Journal, 142, 419-421.

Pešić, Roko (2011). Toplinska smrt svemira. Matematičko-fizički list, 61(3), 178-180.

Ridgen, John S. (2003). Hydrogen: The essential element. Cambridge, Massachusetts: Harvard University.

Rječnik filozofskih pojmova. URL: https://www.filozofija.org/rjecnik-filozofskih-pojmova/ (13. 9. 2018.)

Tauber, Gerald E. (1984). Einsteinova opća teorija relativnosti. Zagreb: Globus.

Veneziano, Gabriele (2012). The Myth Of The Beginning Of Time. Scientific American Time, 21, 78-89.

Vujnović, Vladis (2004). Rječnik astronomije i fizike svemirskog prostora. Zagreb: Školska knjiga. 
The primeval atom of Georges Lemaître

Roko Pešić*

Summary

The paper presents a cosmological hypothesis, the so-called primeval atom hypothesis about the beginning of the universe - the antecedent of the Big Bang theory - of the Belgian priest and professor of physics, Georges Lemaittre, who was in fact Einstein's contemporary, also referred to as the "Father of the Big Bang theory." The significance of this hypothesis is that it is, derived from the partially corrected Einstein equations of the universe, the first scientifically and mathematically developed cosmological model of the origin of space-time continuum and development of the expanding universe which was observationally confirmed soon afterwards by Edwin Hubble and much later by Pensias and Wilson with the discovery of cosmic background microwave radiation. So, until then the commonly accepted static model of the universe became unsustainable, and a new cosmological paradigm was established.

The article briefly describes Lemaitre's main idea based on the concept of the space of variable radius and the assumption of the radioactive origin of some cosmic rays as well as the law of energy degradation (the second law of thermodynamics). The role of Einstein's cosmological constant, the interaction of gravitational force and cosmic repulsion, as well as the later evolution of the universe, formation of clouds of gas, stars and galaxies are described. Finally, the philosophical and metaphysical implications of Lemaitre's hypothesis are mentioned.

The paper is based on the English translation of the original Lemaitre text and is accompanied by notes and clarifications of expert terms. These have been added for the purpose of a more detailed explanation of some sections of the text and will be of interest primarily to cosmologists, physicists and other readers with an astronomy education.

Key words: primeval atom, radioactive decay, Big Bang theory, cosmological model, George Lemaître, expanding universe

* Mr. sc. Roko Pešić, National and University Library in Zagreb. Address: Ulica Hrvatske bratske zajednice 4, p.p. 550, 10000 Zagreb, Croatia. E-mail: roko.pesic@gmail.com 